Michael T. Belongia is a research officer at the Federal Reserve Bank of St. Louis and Kees G. Koedijk is an assistant professor of monetary economics at Erasmus University, Rotterdam, The Netherlands. Anne M. Grubish and Rosemarie V. Mueller provided research assistance.

\title{
Testing the Expectations Model of the Term Structure: Some Conjectures on the Effects of Institutional Changes
}

T term structure of interest rates attempts to explain how interest rates on a similar debt instrument are related across different maturities. It posits that, in a world without risk or one in which assets are perfect substitutes, the one-period interest rate should equal the expected return to holding an instrument of longer maturity for one period. Because the model is based on the most fundamental economic assumptions - rational behavior by individuals who act on all available information - it has held considerable appeal in applied research. Empirical tests for data across a range of countries and sample periods, however, have tended to reject this simple statement of the expectations model. ${ }^{1}$ Moreover, expanding the basic: model by adding other explanatory variables, such as a time-varying risk premium or latent information variables, still has found limited empirical success in explaining interest rate behavior:" Thus, a puzzle remains: why is such a basic theoretical model so frequently rejected by the data?
In this article, using short maturities in the Eurocurrency market, we isolate several institutional factors that might explain some rejections of the expectations model. Altematively, the analysis may be viewed as an attempt to suggest specific characteristics of policy procedures that are inconsistent with the theoretical model's assumptions. Our results suggest that single-country estimates of the expectations model may omit important information because financial markets are highly integrated across countries. Moreover, it appears as if the manner in which monetary policy is conducted has effects on interest rates that contribute to rejections of the theory. In particular, the expectations model does not hold in countries where the central bank - at least periodically - follows an exchange rate rule. Accounting for relationships across markets and for the manner in which monetary policy is conducted reverses, in some cases, the negative conclusion of simple, single equation estimates of term structure relationships.

'For a survey of these results, see Bisignano (1987).

2Examples of work along these lines are Shiller, et al. (1983) and Campbell and Clarida (1987). 


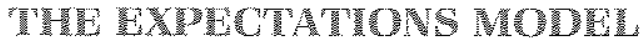

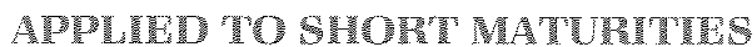

The empirical version of the expectations model can be written as:

(1) $\left(r_{t, 1<1}-r_{1,1}\right)=a+b\left(F_{1,1+1}-r_{1,1}\right)+e_{t}$

where $r_{11}$ is the yield on a one-period bill in period $t$ and $F_{2,+1}$ is the current, observed forward rate on a one-period bill, one period into the future. ${ }^{3}$ Coefficients to be estimated are denoted $a$ and $b$; $e_{f}$ is an error term with zero mean and variance equal fo $\sigma^{2}$. Thus, in equation 1 , the dependent variable is the difference between actual yields on oneperiod bills in consecutive periods and the explanatory variable is the difference between the current forwand and spot rates on one-period bills. Equation 1 predicts that the change in oneperiod yields should be related to the forecasted change, as represented by the forward rate - spot rate spread. The expectations hypothesis implies that, if the forward rate is an unbiased predictor of the future spot rate, the regression's slope coefficient, $b$, should not be significantly different from one and its intercept, $a$, should not be significantly different from zero.

This potentially rich area for empirical research has yielded few definitive results because tests of the expectations model inevitably have been joint tests of several maintained hypotheses. To cite just a few of the problems that arise, the model assumes a zero or constant risk premium. The problem for estimation, however, is that the risk for, term premium - some systematic difference between the long-term interest rate and the expected future values of short-term interest rates that reflects relative degrees of uncertainty - is unobservable. Thus, if an empirical test rejects the hypothesis $a=0$ and $b=1$, it is not possible to discriminate between true model rejection and the possible effects of a term premium that has been assumed, incorrectly, to be zero. In part for this reason, as will be the case below, many stud- ies have chosen to test a weaker form of the expectations model $b=1$ ) and interpret the statistical significance of the regression's intercept as indicating the existence of a tem premium."

There are other testing problems as well. When data for longer maturities are studied, interest rate data often are estimated from a fitted yield curve rather than taken from observed market transactions. In this instance, negative results might be a rejection of the fomula used to approximate unobservable interest rates rather than the expectations model. Finally, the rationality of expectations by market agents is assumed but, again, this is difficult or impossible to test directly. Although more attention has been paid in recent research to models that isolate these assumptions, it remains impossible to say whether negative results indicate a rejection of the expectations model itself or simply one tor more) of its underlying assump. tions.

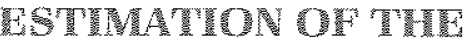 MNPROTAPTONS MODEL}

As noted in the introduction, equations similar to (1) have been estimated with data for many countries and sample periods. We illustrate these results by estimating equation 1 with Hatris Bank data on spot three-month deposit rates from the Eurocurrency market for the U.S. U.K., West Germany, Japan and Switzerland; six-month deposit rates also were used, as explained in footnote 3 , to calculate values for the forward rate. The interest rates are calculated as simple wates. The data are Friday closing quotes lot the Friday closest to the beginning of each month." The sample period spans Februay 1981 through October 1986. Although data prior to 1981 are available, the Euroven makket was thinly truded and, in 1980 , the Carter Administration adopted its Special Credit Control program. Because these factors
For one derivation of this result, see Mankiw and Miron (1986), p. 214 . Stricty speaking, this specification holds up to a con stant (the term premum), which we have ignored. The as+ sumption was that, for the short maturities used in this paper, tem premium effects, if any, should be negligible. Also see Bisignano (1987). Cosset (1982) found that forward fates in this market are unbiased, but not optimal, predictors of future interest rates. He also tound this market to be eflicient in the sense that past information on interest rates is not useful in predicting future values of interest rates.

Values for the forward rate, $F_{t, 1.1}$, were calculated as twice the two-period interest rate minus the one-period rate. Becalise the data in the study use three-month rates to represent the theoretical "one period," the forward rate is calculated as twice the six-month (two period) rate minus the corresponding threemonth rate.

\$See, for example, Shiller, et al. (1983).

5 First-Friday-of-month data, rather than monthly averages of daily or weekly data, were used to avoid questions about how to treat pattial weeks in adjoining months, months with different numbers of weeks and the gap between thee, four-week months and a thirteen week quarter. See Hakkio and Leiderman (1984) for a discussion of these measurement issues. 


\section{Table 1}

\section{Estimates of the Basic Expectations Theory Relationship (monthly data, $1981.02-1986.10$ )}

\begin{tabular}{|c|c|c|c|}
\hline Country & a & 6 & n \\
\hline Whited States & $(0.62$ & $(026)$ & 001 \\
\hline United Kingden & $\begin{array}{l}000 \\
600\end{array}$ & $(0.90$ & 000 \\
\hline & $(3,46$ & $(0,72$ & 0008 \\
\hline & $(0,77$ & $\begin{array}{l}092 \\
1027\end{array}$ & 0.25 \\
\hline Swizerland & $\begin{array}{l}0.23 \\
(0.82)\end{array}$ & $\begin{array}{l}004 \\
201)\end{array}$ & 0.00 \\
\hline
\end{tabular}

NOTE Absolvte values of t stalistcs aro 10 parentheses 1-statstes tor b apoly to the will hypothesis b - 1, Al astersh indicates a siope coefficent signiticanly different trom one at the 0 os level of signitcance

could adversely affect the test results, data prior to February 1981. are not used in estimation."

Finally, a comment on the initial approach to estimation is necessary. Because the data consist of observations on three-month yields sampled monthly, the changes in interest rates overlap and introduce a second order moving average process into the data. Because this property of the data will affect the estimated coefficients' standard errors, it must be considered by the estimation technique. 'The Hansen-Hodrick procedure we use model's error term for serial correlation:

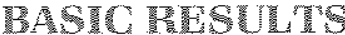

The results from estimating equation 1 are reported in table 1 . The expectations model is clearly rejected for the United States, Germany and Switzerland; their estimated slope coefficients are significantly different from one. In contrast, the results for the United Kingdom and Japan support the expectations model. Explanatory power for the equations is generally low with the notable exception of lapan!. This result is typical in estimates of the expectations model, indicating accounts for this property by correcting the

that interest ate time series closely approximate a random walk. Overall these mixed results represent the typical findings of previous empirical work on the expectations model.

The mixed results in table 1 can be interpreted in two ways. One interpretation is that the expectations model is rejected because it appears not to hold for most of the countries examined. Another interpretation is that institutional or other considerations, which the pure theory regards either as given or unimportant, may have had adverse effects on the empirical tests. Among others, important structual changes that will affect the results include the conduct of L.S. monetary policy, changes in interest rate ceilings and general financial market deregulation. Given the results shown in table 1 , previous research generally has left these results unexplained or has added some ad hoc measure of risk to account for the possible effects of an unobservable term premium. In the sections that follow, we first revise the estimation procedire to see how this change affects the test results. We then discuss some well-defined events and changes in institutions that could affect the term stucture relations and produce the results that appear to reject the model.

\section{ONE POSSIBLE REASON FOR REDECTION OR THE EXPECTATIONG MODEL: CORPELATED ERPOR TERMS}

The increasing integration of world capital markets suggests that an altemative statistical approach should be used to estimate equation 1. As capital flows freely among nations, monetary policy actions (for example) undertaken in one country can be expected to affect financial variables in other countries as well. Consider, for example, a change in Bundesbank policy that affects German interest rates and then is transmitted to interest rates in the other four nations via capital flows caused by the change in German interest rates. This effect, which will appear only in the error term of the German interest rate equation when separate regressions are estimated, could be exploited as a new source of information for each regression if the country equations were estimated

account for the effects of the third-order serial correlation, see Hansen and Hodrick (1980) and Campbell and Clarida (1987)

few data points. The dramatic increase in interest rate volatitity during the first and second quarters of 1980 , relative to the remaining sample, would suggest this sensitivity in OLS re* gression estimates.

For an extensive description of the econometrics used to
EDurbin-Watson statistics are not reported because, as indi" cated in the text, the reported standard errors reflect corrections for serial correlation in the data. 
Table 2

Revised Expectations Model Estimates Using Seemingly Unrelated

Regressions (SUR): 1981.02 - 1986.10

\begin{tabular}{|c|c|c|}
\hline country & a & 6 \\
\hline Unted states & $(2,26)$ & 020 \\
\hline Unted Kngdon & 000 & $\begin{array}{l}0.90 \\
0,20)\end{array}$ \\
\hline Germany & $\begin{array}{r}0.47 \\
(5.62)\end{array}$ & $\begin{array}{l}045 \\
(415)\end{array}$ \\
\hline lapan & 0,18 & $(10,42)$ \\
\hline Switzerand & $\begin{array}{l}0,39 \\
(2,37)\end{array}$ & $(2,19$ \\
\hline
\end{tabular}

NOTE Absolute values of ts statstics are in parentieses. For b the l statistic applies to the nuth typothesis b - 1. An estersk ndicates a slope coefficient significanly different tron one at the 0.05 tevel of significance

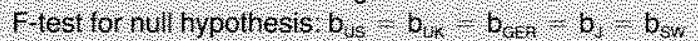
4 is 6 63 compared with a criterl value of 2 . 2 .

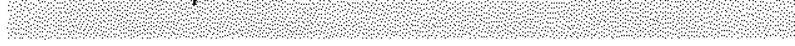

jointly, In other words, the error term of a single equation (which reflects "news," or unpredictable events within that countryl also may contain information - due to linkages among markets - that is relevant to explaining interest rate behavior in another country. The important point is that the expectations model being tested assumes that this information is being used by the rational agents whose collective actions determine changes in interest rates. Single equation estimates, however, exclude the information implicit in these linkages because they look at data for each country in isolation.

One way to account for this missing information is to estimate equation 1 , as applied to the five countries under study, as a system of seemingly unclated regressions (SUR)." This procedure considers contemporaneous correlations that might exist among the error terms of the five equations and, by doing so, improves the efficiency with which the coefficients are estimated.

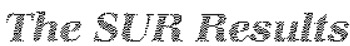

The results from estimating the five equations by SUR are reported in table 2 . 'That important information exists in the elror tems is substantiated by the computed value of 56.34 for a likelihood ratio statistic lesting whether covariances among the eror tems are zero; this value is to bo compared with the 5 percent critical value of 18.30. The error covariance and conelation matrices reported in table 3 indicate where the significant correlations between countries were found. Note, in particular, the high coryelations between the U.S. and Gemmy and between Germany and Switzerland. Conjectures to explain these correlations and possibly, model rejections are discussed later in reference to the table 4 results.

Athough OLS and SUR should produce similar coefficient estimates, both the U.S. and Swiss slope coefficients reported in table 2 are markedly different from their values in table 1 . In view of the low values for $\mathbf{R}^{2}$ in both the U.S. and Swiss equations, however, these changes merely indicate that, for these data, the basic specification of the expectations model simply does not produce precise estimates of the slope coefficient. The more important point is that after using the SUR estimator the hypothesis that all five slope coefficients are jointly equat to one still is rejected. Finally, the Japanese intercept, which dial not change numerically, now is significantly different from zero. Because the German and $\mathrm{U}, \mathrm{K}$. results are largely unaffected by the SUR estimation, however, this simple change in estimation procedure to incorporate linkages among financial markets, while indicating that significant information exists in the correlations among error terms across equations, still rejects the expectations model for most of the countries examined.

\section{OTWEP SOURCES OF EXPLONABLE INTORMATION}

Another assumption behind empirical tests of the expectations model is that the data used for estimation were generated during a period characterized by a stable economic structure. Moreover, the data should be drawn from markets in which interest rates can adjust freely. Thus, the basic model should not be estimated with data from periods associated with major policy

correlation across countries and speculates that captal controls may "prevent effective international arbitrage (p. 66)". See Zellner (1962) for details on the estmation procedure.
${ }^{9}$ Edwards (1982) has made the same point and reported muchimproved results for a similar model applied to the exchange rate. Krol (1987) also reported substantial integration of these markets across countries. Mankiw (1986), however, finds little 
Table 3

Error Correlation and Covariance Matrices From The SUR Estimation

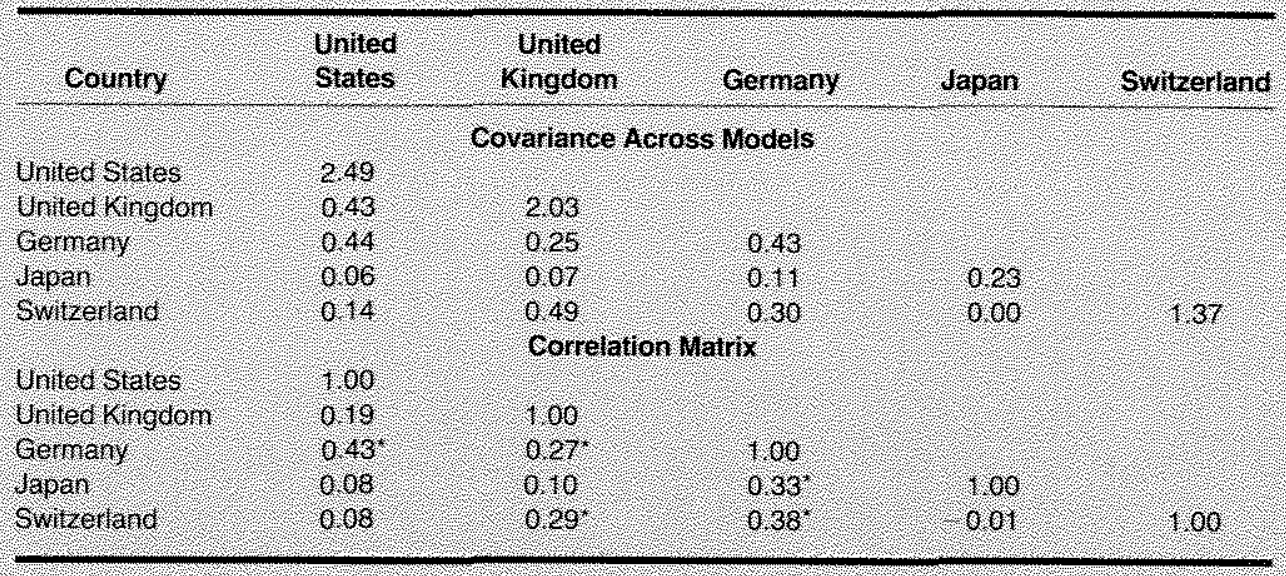

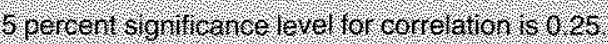

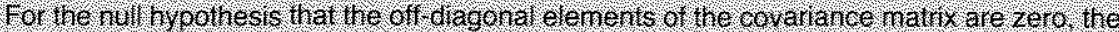

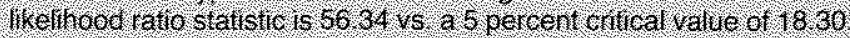

Table 4

\section{Revised Expectations Model SUR Estimates}

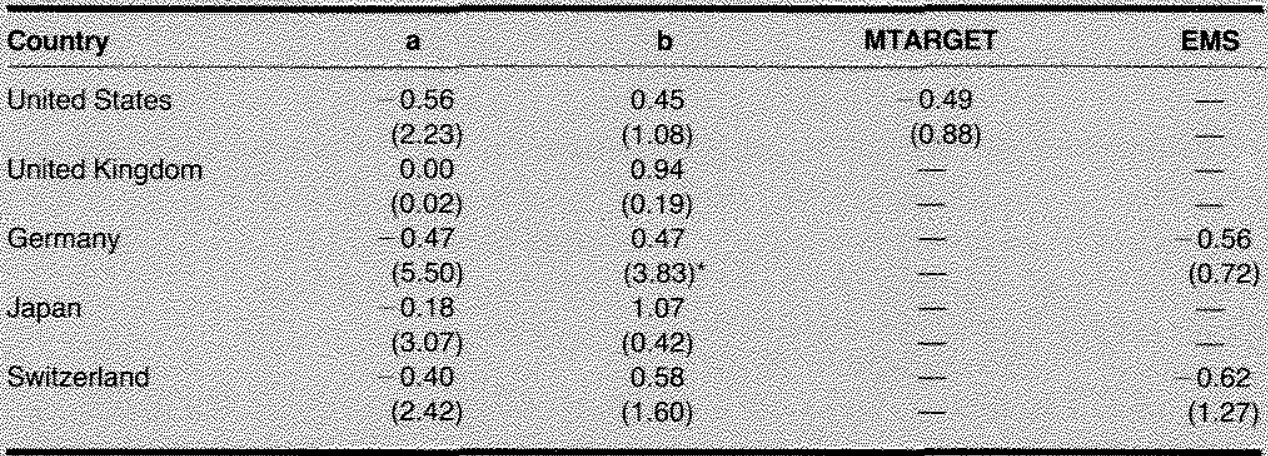

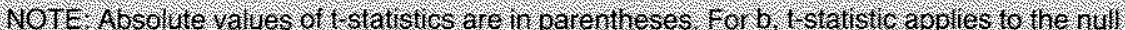

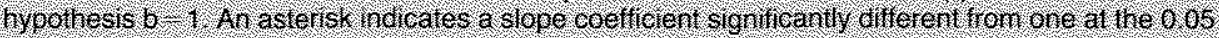
level of signiticance

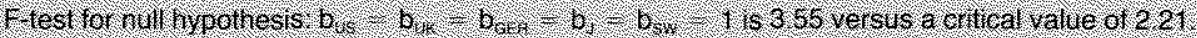

changes or impediments to market adjustments. In the case of the former, major policy changes may cause large discrete changes in expectations or changes in the variability of expectations that cannot be measured ot modelled properly. Similarly, taking data from, say, a period characterized by interest rate controls would be inappropriate for testing the model because theory assumes that interest rates can adjust freely in perfectly competitive, efficient markets. In what follows below, we describe some major changes that have oc- curred during the period used for estimation and assess how they affect the results reported above.

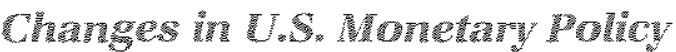

Since October 1979, the Federal Reserve has used two distinct operational procedures in its conduct of monetary policy. Between October 1979 and October 1982, the Fed estabished a targeted path for nonborrowed neserves; this approach permitted short-term interest rates to fluc- 


\section{Chart 1 \\ Changes in Federal Funds Rate}

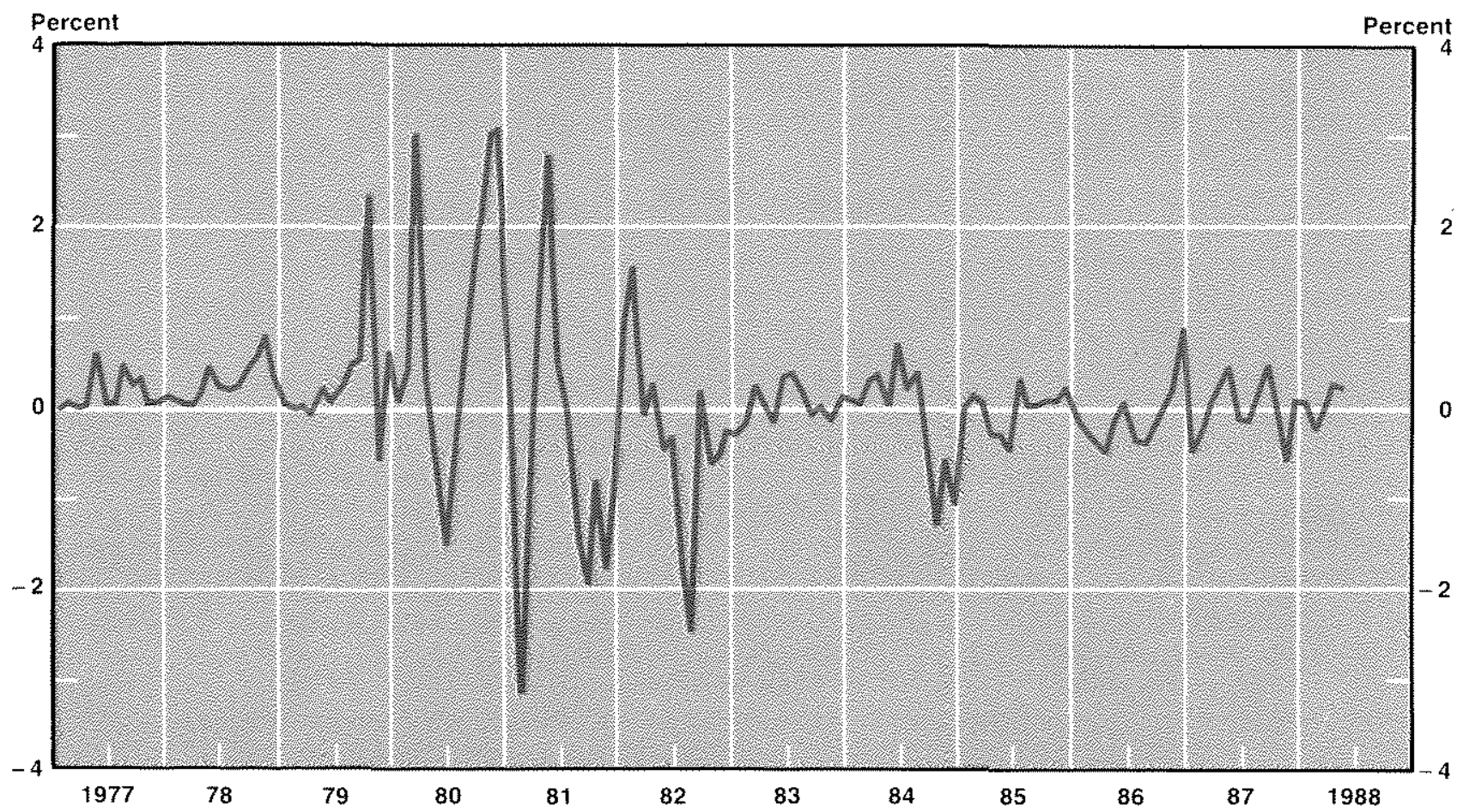

tuate within wider bands than had the previous procedure, which had focused on keeping the federal funds rate within a narrow range. In Octom ber 1982, the Federal Reserve announced that, due to increasing uncertainties about the definition of the M1 aggregate, it would conduct monetary policy by setting an objective for borrowed reserves; this latter strategy resulted in less variation in short-term interest rates. ${ }^{10}$ Thus, the first part of the sample period used in the estimation is characterized by a Fed operating procedure that permitted greater variation in short-ferm interest rates; this period is followed by four years of data associated with a procedure that, once again, reduced the variation in short-term interest rates. The behavion of the federal funds rate, which supports this depiction of events, is shown in chart 1.

How would this switch in policy implementation affect tests of the expectations model? Ac- cording to Mankiw and Miron (1986), Fed policy based on smoothing short-term interest rates can be characterized as:
(2) $\mathrm{E}_{1}\left(\Delta \mathrm{r}_{1+1}\right)=0$

or, the expected change in the short-rate at each moment in time is zero even if the Fed has been observed to change short rates in response to, say, real GNP growth or inflation rates that deviated from prior expectations. If equation 2 describes Fed policy since October 1982 land prior to October 1979), the value of $\left(F_{1,+1}-r_{1+}\right)$ in equation 1 will always be zero and short-term interest rates will behave, approximately, as a fandom walk. In this case, the expectations model of the term structure would be incapable of explaining the behavior of short-term interest rates.

Mankiw and Miron (1986) investigated this problem using annual U.S. data from $1890-1914$ and

10 See Wallich (1984) and Gilbert (1985) for more discussion about changes in the implementation of U.S. monetary policy over time. 
1915-79. They found that support for the expectations model varied with monetary regime. While the expectations model "holds" for the pre-fed period, when there was no monetary anthority to smooth interest rates, the model is rejected for the later period when the Fed's approach to policy tended to smooth fuctuations in short-tem interest rates. Their results, therelore, suggest that the U.S. results reported in lable 2 - and perhaps other rejections of the model using post-1979 U.S. data - could be dominated by the sub-sample associated with the post-October 1982 change in federal Reserve operating procedures.

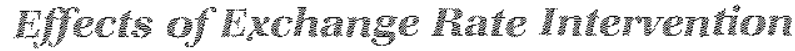

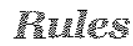

The founding of the European Monetary System (EMS) is another important change that occurred in 1979 and is a possible source of the negative results for Gomany and Switzerland. The EMS agreement established ranges for bilateral ex change rates of the member countries and called for cooperative interventions by the central banks of the countries involved when rates deviated from their specified ranges. Thus, German monetary policy since 1979 has been constrained by its participation in the exchange rate agreement and its pledge to intervene." In practice, Gemany has become the leader of the EMS due to the size of its economy and its low inflation mat other EMS countries have followed its noninflationary monetary policy. Much research has shown that the EMS agreement really has behaved as if a dollary DM objective were pursued by the German central bank. ${ }^{12}$

In addition, swiss monetary policy is influenced by the DM/Swiss franc exchange date even though Switzerland is not an EMS member." Because standard models typically explain the behavior of the exchange rate as depending on the spread between foreign and domestic interest rates, attempts by the Bundesbank to influence the dollar DM exchange rate also would create a strong link between Geman and Swiss interest rates. ${ }^{14}$ Suppose, for example, that the dollar were depreciat ing against the DM because U.S. interest rates were falling. Fhe Bundesbank could attempt to stop or reverse this dollar depreciation by expanding the German money stock and lowering German short* term interest rates. Such an action, however, would cause the value of the Swiss franc to rise against the DM. In the past, the Swiss National Bank has responded to this (or similar) sequence of events by following the Bundesbank with a more expansionary monetary policy and lower. short-tem interest rates as it attempted to reestablish some desired value for the DM/Swiss franc exchange rate. This close linkage of German and Swiss interest rates, from a Swiss objective for stability of the bilateral exchange rate, is likely to be the source of the highly correlated Swiss and Geman error terms reported in table $3 .^{1.5}$ In sum, both German and Swiss monetary polieies are influenced by exchange rate considerations that could affect empirical estimates of the expectations model.

\section{Empunical Implementation}

"F investigate these possibilities, the system of SUR equations reported in table 2 was reestimated with changes in the U.S., German and Swiss regressions. For the U.S, the whole-sample slope coefficient was split to represent the two distinct periods of Federal Reserve operating procedures. A slope dumny (MTARGET) was introduced, which took a value of one between February 1981 and september 1982 and a value of zero for the remaining months. If the Mankiw-Miron hypothesis is correct, the slope coefficient for the first part of the sample (b plus MTARGET) should not be significantly different from one while the coefficient for the latter period $t b$ alone should be significantly different lless than from one.

Although the precise way to quantify the impact of the EMS agreement on German and Swiss financial markets is not clear, the periods when the

\footnotetext{
${ }^{11}$ The history of the EMS and a discussion of how it functions can be found in Ungerer, et al. (1986).

"See, for example. Fels (1987) for a discussion of the EMS as a dollar/DM commitment by the Bundesbank.

13Because trade represents 39 percent of Swiss GDP and trade with Germany accounts for one-fifth of total trade, the Swiss franc DM exchange rate has been particularly important to the conduct of Swiss monetary policy. The Swiss National Bank, at times, has abandoned its objectives for the growth rate of the monetary base and, instead, pursued an exchange rate objective. See Rich and Béguelin (1985).

${ }_{14}^{14}$ See, for example, the model presented by Dornbusch (1980).
}

${ }^{15} \mathrm{~A}$ related point that suggests this sort of influence across countries is based on results from Belongia and Oft (1988). They show that the dollar exchange rate risk premium and the amount that the exchange rate adjusts to a given domestictoreign interest differential both vary with the choice of Federal Reserve operating procedure (interest rate vs. money stock objectives). If nothing else, their result would be suggestive of a time varying risk premium in the expectations model

${ }^{15}$ An intercept dummy aiso was tried but it was not significant individually and had no material effects on the magnitudes or significance of ther coefficients. 
member countries agreed to major realignments of the official exchange rate levels and ranges are known. Other things the same, one can hypothesize that interest rates made discrete adjustments to these realignments within one month after they were announced. To test the proposition about exchange rate linkages and interest rates, a dummy variable was created to represent EMS realignments and was introduced into both the Gemman and Swiss regressions. This vatiable took a value of one during the months associated with the eight EMS realignments and a value of zero during all other months. ${ }^{17}$ As with the U.S. case, multiplying the forward rate - spot rate spread in the German and Swiss regressions by this dummy variable permits the estimation of two different values for the regressions' slope coefficients: one coefficient for "normal" periods and the sum of two coefficients for months when a realignment occurred.

In table 4, the revised SUR results are reported. The null hypothesis that all five slope coefficients are jointly equal to one is rejected, once again, at the 0.05 level of significance. The expectations model is rejected even after augmenting the information set to incorporate changes in the implementation of U.S. monetary policy and the EMS realignments.

Looking at individual country results, the table's top row, associated with the slope dummy for the period of monetary targeting in the United States, indicates that estimates of the expectations model are sensitive to changes in the Fed's operating procedure. Even though the MTARGET dummy is not significant, the model's whole-period slope coefficient increases from 0.20 to 0.45 and now is not significantly different from one.

This apparent improvement in the U.S. results, however, is in direct contrast to Mankiw and Miron's results in two respects. First, when they attempted to investigate the effects of post-1979 data on the expectations model, they reported that "we obtain standard errors so large that one can reject no interesting hypothesis" (p. 227). More important, they hypothesized that the expectations model should not be rejected for the period of money stock targeting, but should be rejected for the post-September 1982 period; enpirically, this implies that b plus MTARGET should not be statistically different from one while batone should be significantly different from lless than! one, In fact, the result are reversed; the expecta tions model is rejected for the period of money stock targeting. Thus, while the dummy vatiable improves the overatl results and provides perhaps a stronger test of their model, the exact process at work is inconsistent with the one hypothesized, leaving an unexplained puzzle.

The revised estimates for the German and Swiss equations provide weak support for the conjecture that the intervention policies of their central banks have significant effects on tests of the expectations model. The signs on the slope dummies are negative and similar in magnitude, to the whole period slope coefficient, which indicates that the forward rate-spot rate spread has zero effect during months of EMS realignments. Moreover, the whole period swiss slope coefficient now both is larger numerically and not significantly different from one. For Gemany, however, the results are not altered when the dates of EMS realignments are considered and the data continue to reject the expectations model.

\section{CONCHUSONS}

The expectations model of the term structure of interest rates has been applied to data for a number of countries and sample periods with generally negative results. In this article we have investi gated some conditions under which the expectations model might be rejected in the context of its traditional single equation test. We found substantial correlations across the errors of the individual equations which, when exploited by using SUR estimation, improved the efficiency of estimation. We also found that, ahhough dummy variables used to represent changes in the approach to monetary policy or EMS exchange rate targets were not significant individually, they contributed somewhat to improved overall characteristics of the equations. Although, as in previous studies, many puzzles still remain, these results suggest that tests of the expectations model should use more general models and more efficient estimation procedures than the simple OLS equation typically employed.

${ }^{17}$ The dates of EMS realignments were March 23 and October 5 , 1981; February 22 and June 14, 1982; March 21, 1983; July 22, 1985; April 7 and August 4, 1986 and are provided in Fels, p. 217. 


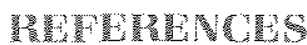

Belongia, Michael T., and Mack Ot. "The U.S. Monetary Policy Regime, Interest Differentials and Dollar Exchange Rate Risk Premiar" Joumal of International Money and Finance, (December 1988), forthcoming.

Bisignano, Joseph R. "A Study of Efficiency and Volatility in Government Securities Markets." Bank for International Settements, processed June 1987.

Campbell, John Y., and Richard H. Clarida. "The Term Structure of Euromarket Interest Rates: An Empirical Investigaton," Journal of Monetary Economics (January 1987), pp. 25-44.

Cosset, Jean-Claude. "Forward Rates as Predictors of Future Interest Rates in the Eurocurrency Market, "Journal of Imternational Business Studies (Winter 1982), pp. 71-83.

Dornbusch, Rudiger. "Exchange Rate Economics: Where Do We Stand?" Brookings Papers on Economic Activity (1980:1), pp. $145-85$.

Edwards, Sebastian. "Exchange Rates and 'News': A Multi" Currency Approach," Joumal of International Money and Finance (December 1982), pp. 211-24.

Fels, Joachim. "The European Monetary System 1979-87: Why Has 11 Worked?" Intereconomics (September/October 1987), pp. 216-22.

Gilbert, R. Alton. "Operating Procedures for Conducting Monetary Policy," this Review (February 1985), pp. 13-21.

Hakkio, Craig S., and Leonardo Leiderman. "Intertemporal Asset Pricing and the Term Structure of Exchange Rates and Interest Rates: The Eurocurrency Marke:, European Economic Review (April 1986), pp. 325-44.

Hansen, Lars P., and Robert J. Hodrick. "Forward Exchange Rates as Optimal Predictors of Future Spot Rates: An Económetric Analysis," Joumal of Political Economy (October 1980), pp. $829-53$.
Krol, Robert. "The Interdependence of the Term Structure of Eurocurrency interest Rates," Journal of International Money and Finance (June 1986), pp. 245-53.

Mankiw, N. Gregory, and Jeftrey A. Miron. "The Changing Behavior of the Term Structure of Interest Rates," Quarterly Joumal of Economics (May 1986), pp. 211-28.

Mankiw, N. Gregory. "The Term Structure of Interest Rates Revisited," Brookings Papers on Economic Activity (1:1986), pp. 61-96.

Rich, Georg, and Jean-Pierre Béguelin. "Swiss Monetary Policy in the 1970s and 1980s: An Experiment in Pragmatic Monetarism," in Monetary Policy and Monetary Regimes, Center Symposium Series, CS-17, Karl Brunner, ed., Center for Research in Government Policy and Business, University of Rochester (1985), pp. 76-111.

Shiller, Robert d., John Y. Campbell, and Kermit L. Schoenholtz. "Forward Rates and Future Policy: Interpreting the Term Struciure of Interest Rates," Brookings Papers on Economic Activity (1:1983), pp. 173-217.

Wallich, Henry C. "Recent Techniques of Monetary Policy," Federal Reserve Bank of Kansas City Economic Review. (May 1984), pp. $21-30$.

Ungerer, Horst, Owen Evans, Thomas Mayer, and Philip Young. The European Monetary System: Recent Developments, Occasional Paper No. 48 (International Monetary Fund, December 1986).

Zelner, Arnold. "An Efficient Method of Estimating Seemingly Unetated Regressions and Tests for Aggregation Bias," Journal of The American Statistical Association (June 1962): pp. 348-68. 